\title{
Mast cell a new player in Type 2 diabetes EP476
}

Diabetes (Therapy and complications )

Cairo University

Nehal Hamdy* ,Randa F Salam* ,Nagwa Abd EL-Ghaffar Mohamed ${ }^{* *}$, Eman Mahmoud Hassan ${ }^{* *}$

Departement of Internal Medicine Cairo University* ,Department of Clinical and Chemical Pathology, National Research Center, Cairo, Egypt**

\section{Introduction}

Mast cells are critical effectors in inflammatory diseases, including cardiovascular and metabolic diseases and their associated complications. These cells exert their physiological and pathological activities by releasing granules containing histamine, cytokines, chemokines, and proteases, including mast cell-specific chymases and

\section{Objectives}

Aim of the study is to detect the role of mast cell in diabetic obese and correlation to different diabetic complications

\section{Methods}

70 Type 2 diabetic obese patients attending the Diabetes and Endocrinology clinic in Kasr El Ani hospital compared to 15 healthy control.

Full medical history, complete physical examination, Anthropometric measurements (BMI, waist circumference)

Michigan neuropathy score,Echo heart, fundus examination, fasting glucose, $\mathrm{HbA1C}$. serum cholesterol

.triglycerides,LDL,,HDL , A/C ratio and Typtase level

\section{Results}

Statistical difference between patients and control regarding BMI,glucose,cholesterol,HDL,LDL,tryptase $(p<0.001)$ ,triglycerides $(p=0.001)$.Tryptase correlated with $\mathrm{BMI}$,fasting glucose ,HbA1C,triglycerides which is statistically significant $(p=0.014, r=0.031) /(p=0.012, r=0.297) /(p<0.001, r=0.862),(p=0.039, r=0.247)$.Tryptase is higher in patients with complication mean value $(39.32 \pm 4.9) \mathrm{ng} / \mathrm{ml}$. 4 patients with retinopathy , 6 patients with peripheral neuropathy, 3 patients diabetic nephropathy, 8patients with ischeamic heart disease , 3 patients with cerebro vascular disease
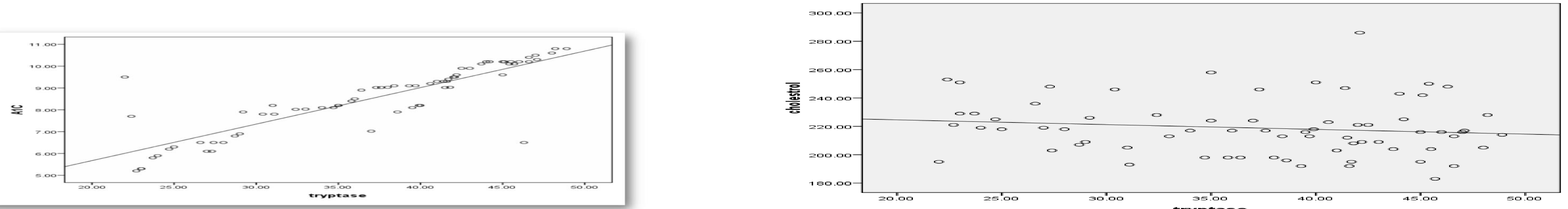

\section{Conclusions}

Tryptase participate in the pathogenesis of diabetes mellitus and its complication targeting mast cells as novel therapy for diabetes requires further investigations

Michael A. Shi and Guo-Ping Shi Different roles of mastcells in obesity and diabetes:lessons from experimental animals and humans . frontiers in immunology $.2012 \mid(3): 7-11$

Harvima,T, Francesca Levi-Schaffer, PharmD, Petr Draber, et al . Molecular targets on mast cells and basophils for novel therapies J Allergy Clin Immunol 2014;134:530-44.) 